\title{
Psiconologia: O Estudo das Imagens Produzidas pela Psicologia à Luz da Iconologia de Mitchell
}

\author{
Danilo Sergio Ide* \\ Universidade de São Paulo, São Paulo, SP, Brasil
}

\begin{abstract}
RESUMO - Na psicologia, o fenômeno imagético tem sido debatido tradicionalmente nos domínios da psicologia da arte e da psicologia da imagem. Aqui, incorporamos a tal debate a iconologia de Mitchell, centrada no estudo discursivo do imagético. Trabalhando com um levantamento de projetos de pesquisas psicológicas na Avaliação CAPES 2012 que versavam sobre o fenômeno imagético, extraímos, a partir de recorrências discursivas encontradas nos resumos de tais projetos, seis unidades temáticas - imagem-mente, imagem-representação, imagem-estímulo, imagem-registro, imagemexpressão, imagem-produção -, caracterizadas por associações iconológicas específicas. Da última, imagem-produção, localizamos um campo merecedor de investigação particular, voltado ao debate sobre a produção imagética no interior da própria psicologia, cuja relevância se coloca hoje pelo crescente recurso aos métodos visuais, e que intitulamos psiconologia.
\end{abstract} PALAVRAS-CHAVE: imagem, discurso, métodos visuais, psicologia

\section{Psiconology:The Study of Images Produced by Psychology in Light of Mitchell's Iconology}

\begin{abstract}
In Psychology, the pictorial phenomenon has traditionally been debated in the fields of art psychology and psychology of images. We added to the discussion Mitchell's Iconology, centred on the discursive study of images. We worked with research projects in psychology found in the CAPES (Brazilian Federal Agency for Support and Evaluation of Graduate Education) Evaluation of 2012 dealing with pictorial phenomenon. From the abstracts of these projects, we extracted six thematic units - image-mind, image-representation, image-stimulus, image-record, image-expression, imageproduction - defined by specific iconological associations. From the latter, image-production, we identified a field worthy of specific research: the debate about pictorial production within the very field of psychology, significant today because of the increasing use of visual methods and something which we called psiconology.
\end{abstract}

KEYWORDS: image, discourse, visual methods, psychology

O trabalho ora apresentado estabelece como objeto as imagens produzidas pela psicologia, cuja relevância pode ser notada por uma nova tendência que ganha força na pesquisa psicológica: o psicólogo tem produzido não somente textos, como também imagens, em geral, trabalhadas junto com os próprios participantes das pesquisas desenvolvidas. A psicologia se coloca neste momento diante de um novo objeto de pesquisa, cujo estudo nos remete a problemas teóricometodológicos fundamentais ainda pouco explorados: Como se dá o processo de produção de imagens na psicologia? Por que o psicólogo recorre agora a imagens além de textos? Quais os significados por ele atribuídos aos recursos visual e textual? (Há diferença entre ambos? Qual é o particular atribuído à imagem produzida? Qual é o particular atribuído ao texto produzido?).

A psiconologia representa nosso esforço de constituição de um campo para abrigar o estudo dessas imagens que vem sendo produzidas pela psicologia. Na tarefa de melhor delineá-la, recorremos ao diálogo com outros três campos de pesquisa que lhe são coetâneos: (1) a psicologia da arte, campo dentro do domínio geral da psicologia que tradicionalmente abrigou o estudo da imagem (dentre os problemas subjacentes à psicologia da arte estaria o exame do que se entende por arte); (2) a psicologia da imagem,

\footnotetext{
*E-mail: daniloide@usp.br

- Submetido: 02/09/2015; Revisado: 03/03/2017; Aceito: 04/04/2017.
} 
campo em parte derivado da psicologia da arte, decorrente da correspondência incompleta entre o fenômeno artístico e o fenômeno imagético, já que nem toda obra de arte é uma imagem e nem toda imagem é uma obra de arte (dentre os problemas subjacentes à psicologia da imagem estaria 0 exame do que se entende por imagem); (3) a iconologia desenvolvida pelo crítico literário e historiador da arte William J. T. Mitchell, que trata das afinidades entre imagens e textos, campo especialmente útil à psicologia da imagem, já que o exame do que se entende por imagem inclui o estudo empírico do que foi dito de determinada imagem, ou seja, o levantamento dos discursos produzidos em sua leitura.

Antes de prosseguir, cabe justificar a escolha desses três campos particulares. A psicologia da arte e a psicologia da imagem contemplam, grosso modo, a via estética mais estabelecida da reflexão sobre a imagem no interior da psicologia e compõem, em particular, as linhas de constituição da Psicologia Social da Arte praticada no Laboratório de Estudos em Psicologia da Arte, sediado no
Instituto de Psicologia da USP, dirigido primeiro por João A. Frayze-Pereira e depois por Arley Andriolo. Da psicologia da arte e psicologia da imagem para a iconologia há um percurso cuja direção já fora apontada por Andriolo (2014) ao destacar o componente discursivo na reflexão estética da imagem.

Para assinalar tal diferença de abordagem, vale apontar, apoiados em Ginzburg (1986/2007), a origem da iconologia, no interior do Instituto Warburg, sediado em Londres, fundado por Aby Warburg e que teve entre seus pesquisadores as figuras de Erwin Panofsky e Ernst Gombrich. Sobre o Instituto Warburg, devem-se marcar suas raízes no solo da história da arte, tomada menos pelo trabalho de classificação e ordenação de escolas artísticas do que pela consideração das fontes figuradas como documentos históricos. A iconologia se configura, então, num trabalho dividido entre fontes textuais e fontes figuradas que fazem do imagético um fenômeno não apenas ligado ao estético, mas também ao discursivo.

\section{DELINEAMENTO DA PSICONOLOGIA NO DIÁLOGO COM OUTROS CAMPOS}

\section{Psicologia da Arte}

A participação da psicologia no estudo da imagem esteve comumente atrelada aos avanços da psicologia da arte, campo cuja constituição passa particularmente pelas obras de autores como Gustav Fechner, Wilhelm Wundt, Rudolf Arnheim, Ernst Gombrich, Ernst Kris, René Huyghe, Mário Pedrosa e Nise da Silveira, entre outros. O próprio João A. Frayze-Pereira (1994), justamente quem estabeleceu esse fio condutor entre autores tão diversos para configurar o campo da psicologia da arte, merece figurar nesse quadro pela destacada contribuição em variadas pesquisas que conduziu e orientou no Laboratório de Estudos em Psicologia da Arte.

O campo da psicologia da arte, centrado, em particular, nos processos de criação, crítica e recepção de obras de arte, estabeleceria ao estudioso da imagem um limite quanto aos seus possíveis objetos de estudo, circunscritos então às imagens ligadas ao fenômeno artístico. Tal recorte não compreende a totalidade do fenômeno imagético, cada vez mais ampliado com o avanço da fotografia, cinema, televisão, vídeo, computador e redes digitais. É certo que essa ampliação repercute no fenômeno artístico (a arte não é indiferente a tais mídias e delas se apropria, o que, por fim, provoca mudanças no que se entende por arte), mas a imagem se desdobrou em variados contextos e a imagem artística se tornou um dos tipos dentro do quadro geral do que se entende por imagem. Aqui começa a ser esboçada uma distinção entre os interesses de uma psicologia da arte, voltados particularmente ao fenômeno artístico, e os interesses de uma psicologia da imagem, voltados ao fenômeno imagético, distinção essa que se revela significativa por abrir espaço para investigação de novos objetos imagéticos, independentemente de seu reconhecimento como obras de arte.

\section{Psicologia da Imagem}

A derivação de uma psicologia da imagem a partir da psicologia da arte representa uma nova orientação no Laboratório de Estudos em Psicologia da Arte decorrente da iniciativa do seu atual coordenador, Prof. Arley Andriolo. Tal virada percorre as linhas de seu mais recente artigo detido sobre as imagens do inconsciente, "imagens fabulosas originárias da experiência de criadores das classes populares, vinculados ou não ao hospital psiquiátrico, cuja vontade incontrolável de expressão plástica e a produção imagética interpelam o próprio campo artístico" (Andriolo, 2014, p. 92). Mais uma vez, estamos diante de um objeto caro à psicologia da arte, sobretudo na história do laboratório, desde a seminal tese de doutorado de Frayze-Pereira, defendida em 1987, que tratava da exposição de arte incomum na XVI Bienal de Arte de São Paulo e sua recepção pelo público. Parece mesmo natural a atração duradoura da psicologia da arte por tal objeto, pois ele interroga justamente o que se entende por arte. Como classificar essas imagens cujo estatuto artístico não é majoritariamente reconhecido, mas ainda assim se vinculam expressivamente com o fenômeno artístico, já que provocam efeitos estéticos no público e movimentam inclusive o discurso da crítica de arte? Seriam obras de arte ou obras da loucura?

$\mathrm{O}$ objeto de estudo, embora mantido, recebe no artigo de Andriolo o tratamento de uma abordagem distinta, o que 
adquire um valor programático para marcar a transição da psicologia da arte para a psicologia da imagem. Lá estão as imagens do inconsciente, mas o artigo se serve delas menos para ampliar o debate entre arte e loucura, como seria do interesse da psicologia da arte, do que para destacar a relação intrincada entre imagens e textos, marcada por confrontos entre diferentes discursos produzidos no processo de leitura das imagens: de um lado, a "iconografia psicopatológica" (Andriolo, 2014, p. 105), exemplificada pelo discurso psiquiátrico que toma as imagens do inconsciente como texto cifrado cuja chave para decodificação seria dada pelo conhecimento psicopatológico do psiquiatra; de outro lado, a "iconologia crítica" (Andriolo, 2014, p. 106), que expõe os limites da iconografia psicopatológica ao convocar outras fontes, não apenas textuais (o que escreveram Nise da Silveira ou Mário Pedrosa sobre as imagens do inconsciente), como também figurativas (diferentes séries de desenhos feitos por Rubens, interno do Juquery).

\section{Iconologia}

A transição da psicologia da arte para a psicologia da imagem avança também com o emprego de termos até então pouco habituais no debate sobre as imagens do inconsciente: iconografia e iconologia. Tais termos remontam ao trabalho do historiador da arte Erwin Panofsky, justamente quem estabeleceu a distinção entre ambos. Entretanto, aqui se trata de outra referência, que são os trabalhos de W. J. T. Mitchell, autor que reconfigurou o campo da iconologia de uma ciência interpretativa dos significados profundos da arte renascentista, estabelecida justamente por Panofsky (1955/1976), para uma ciência das imagens, consideradas num sentido mais amplo, centrada na imbricação entre imagens e textos ou seguindo as próprias formulações de Mitchell, o "estudo do logos (as palavras, ideias, discursos, ou ciência) dos ícones (imagens, quadros, ou similitudes)" (1986, p. 1); o "estudo do campo geral das imagens e sua relação com discursos" (1994, p. 36).

A generalidade do campo das imagens é reforçada na iconologia de Mitchell (1994) pela escolha de objetos variados: desenhos, cartoons, capas de revistas, pinturas, filmes. Contudo, a diferença em relação à Panofsky não se encerra no objeto de pesquisa. O método iconológico de Panofsky se voltava à interpretação do texto no interior da imagem. No nível iconográfico, identificava textos ilustrados pela pintura renascentista, a partir de questionamentos como, por exemplo, qual fonte literária (clássica, mitológica ou medieval, cristã) orientou a configuração dos motivos e temas retratados pelo artista? Alguns exemplos desse tipo de leitura das imagens são fornecidos pelo autor: o retrato da águia de Júpiter baseada nos motivos da águia de São João Evangelista ou da pomba de São Gregório indicava o emprego de uma fonte literária adulterada, que interpretava personagens mitológicos segundo a moral cristã; o retrato de Cristo puxando Adão do Limbo baseado no motivo de Hércules trazendo o cão Cérbero do Hades seguia a tendência então vigente das traduções "moralizadas" (Panofsky, 1955/1976, p. 72) de temas pagãos, oriundos da mitologia, para temas cristãos. Já no nível iconológico, estabelecia a relação entre pintura e o espírito da época. Nesse caso, a pintura era tomada como um sintoma cultural e, assim, lida como um documento revelador da história da cultura. Panofsky exerce essa interpretação iconológica a partir da leitura conjunta de dois fenômenos que marcaram a espiritualidade do homem renascentista. Para o autor, a distância do observador, incorporada por um "sistema moderno de perspectivas" (Panofsky, 1955/1976, p. 83), oferecia o contraponto estético do distanciamento entre renascimento e antiguidade reconhecido por uma "ideia moderna de história” (Panofsky, 1955/1976, p. 83).

A reconfiguração da iconologia por Mitchell considera igualmente a relação entre imagem e texto, mas, diferente da abordagem de Panofsky, os textos não estão escondidos na imagem à espera de decifração, sendo tarefa do intérprete levantar diversas fontes literárias em busca de uma chave de leitura. Para o autor, tal projeto iconológico se torna uma ideologia, "um sistema de naturalização" (Mitchell, 1994, p. 30, tradução nossa), baseado na construção de uma narrativa mestra de leitura que naturaliza a diferença entre imagens e textos e apaga o conflito, a resistência do ícone ao logos, pois, se, de um lado, as imagens são assimiladas em conexão com textos, demandando palavras para sua interpretação, de outro, elas resistem a serem interpretadas e vertidas em palavras. Na tentativa de dobrar essa resistência, é organizado um discurso que nem sempre nos aproxima da imagem e do qual se depreende uma retórica própria que revela mais a atitude muito particular de seu intérprete. A iconologia crítica, tal como a denomina Mitchell, prevê uma mudança de método. Ao invés de propor uma narrativa mestra interpretativa da imagem, investiga a relação entre artes verbais e visuais a partir da análise da retórica dos textos que tratam de imagens. Quando se fala sobre imagens, que expedientes os autores recorrem para formular seus juízos sobre elas? Como se organizam os textos que tratam de imagens?

A iconologia estabelecida por Mitchell como uma ciência do campo geral das imagens amplia a variedade de objetos que merecem a atenção do iconólogo ou iconologista, dentre os quais um tipo particular de imagem interessa diretamente aos psicólogos, que é aquela produzida pela própria psicologia como alternativa aos recursos textuais, a exemplo da antropologia visual, que há mais tempo lida com tais debates entre imagens e textos e já conta com produções imagéticas, dispondo de laboratórios e grupos de pesquisa organizados (no Brasil podemos destacar o Laboratório de Imagem e Som em Antropologia da USP e o Núcleo de Antropologia e Imagem da UERJ), periódicos voltados ao tema (como os Cadernos de antropologia e imagem) e inclusive festivais de cinema (como a Mostra internacional do filme etnográfico e o forumdoc.bh-Festival 
do filme documentário e etnográfico/ Fórum de antropologia e cinema). A importância da imagem nas ciências humanas já havia sido formulada por Mitchell (1994) com a expressão "pictorial turn" (p. 11). Os métodos visuais, que derivam de tal virada imagética ou reviravolta pictórica, cada vez mais se apresentam na psicologia (cf. Ide, 2014a). O emprego de desenho, fotografia e vídeo se tornou inclusive um objeto de pesquisa no programa de pós-graduação em psicologia da UFAL, no projeto "A imagem na investigaçãointervenção de processos psicossociais", coordenado pela Prof. Adélia Augusta Souto de Oliveira. O Laboratório de Estudos em Psicologia da Arte também se abriu a esse tipo de experimentação com imagens produzidas no âmbito de pesquisas psicológicas, como na tese de doutorado Perambulações no bairro da Liberdade: passeios ao vivo e em vídeo com moradores locais (Ide, 2014b) e no projeto de mestrado Uma pesquisa visual e compartilhada de Paraty:
Fotografias e narrativas de representação da cidade, de Ligia Ungaretti Jesus (2015).

A psicologia já conta, portanto, com uma produção razoável nesse sentido, o que torna mais do que necessária e oportuna a investigação das imagens produzidas por ela. Assim, é nesse contexto ainda incipiente que se insere nosso trabalho. Esperamos oferecer uma contribuição para área da psicologia com a organização de um campo original de estudo, a psiconologia, entendida como uma iconologia particular caracterizada pelo estudo dos discursos sobre as imagens produzidas pela psicologia. A formação desse campo representaria uma importante conquista, já que o psicólogo, que nem sempre encontra espaço nos já existentes foros de debate sobre a produção de imagens no campo das artes e da comunicação, encontraria um foro especial de debate no interior do próprio domínio da psicologia.

\section{PRIMEIROS PASSOS NA ORGANIZAÇÃO DO CAMPO DA PSICONOLOGIA}

\section{Desafio Metodológico}

A constituição do campo da psiconologia passa pelo enfrentamento de um desafio associado ao estudo da imagem: Como constituir uma iconologia sem transformá-la numa ideologia?

Entenda-se aqui iconologia como produção discursiva sobre imagens e ideologia, como discurso que se faz totalitário, impondo-se a despeito de suas brechas, ou, nas palavras de Mitchell (1994), "uma formação cultural, histórica disfarçada como um código universal, natural" (p. 31, tradução nossa). Amparados ainda nas linhas do autor, compreendemos que lidar com a imagem requer um discurso, cujo trabalho de estruturação para erigi-lo se presta tanto à sua coerência quanto à sua naturalização, o que envolve um risco, daí a necessidade de uma iconologia crítica, que não perca de vista o caráter próprio ao discurso: perspectivo, pontual e lacunar. Essa seria uma formulação bem resumida das elaborações trazidas por Mitchell, em cuja iconologia se observa um lastro moderno, caracterizado pela suspeita diante de grandes narrativas e suspensão dos referenciais firmemente ancorados na tradição, com a crescente afirmação da multiplicidade de posições discursivas. Na iconologia de Mitchell, certamente não opera o princípio relativista de que todas as posições discursivas possam ser equiparadas, tampouco a ambição de eleger imagens apenas para lhes atribuir leituras inauditas. Isso fica patente em Iconology, no qual Mitchell (1986) sequer recorre a figuras ao longo da obra, mas o projeto de marcar o quanto os tratos singulares sobre imagens iluminam as próprias, bem como a posição discursiva de seus leitores. Em Picture theory, no qual Mitchell (1994), por sua vez, recorre de modo programático a figuras, o recurso às imagens não visa expor a leitura que o autor faz delas. Por exemplo, quando retoma As meninas, não o faz para adicionar mais uma interpretação à notória obra de Velázquez, mas para iluminar o modo singular de trabalho de Foucault ao abordála, distinto do modo de um historiador de arte.

A constituição de uma iconologia crítica corresponde a um desafio ao qual um psicólogo detido sobre o estudo da imagem deve se ater. No último encontro nacional da Associação Brasileira de Psicologia Social (ABRAPSO), ocorrido em 2013, foi organizado um grupo de trabalho próprio para a discussão do tema, intitulado Psicologia Social, Arte e Imagem no mundo contemporâneo: Intervenções, invenções e produção de conhecimento em psicologia social. Um dos questionamentos levantados durante as atividades do grupo de trabalho se referiu às possibilidades de análise de uma imagem. A constatação era a de que os psicólogos, por vezes, ficam reticentes ou mesmo inseguros com o que podem falar diante de uma imagem, como se a psicologia tivesse pouco a dizer e o único discurso competente sobre o fenômeno imagético proviesse de outros domínios. Em consequência disso, uma das posições saudadas no grupo de trabalho foi a necessidade de empreender uma incursão a campos tradicionalmente engajados no estudo da imagem, como as artes e a comunicação, o que seria um movimento natural e salutar, não fosse a tendência a extrair dos textos oriundos da estética, crítica, história da arte e teoria da comunicação um tipo de repertório que pudesse ser útil na composição de uma narrativa mestra capaz de domar as imagens. Justamente aqui identificamos a formulação de uma ideologia no lugar de uma iconologia, pois, na ânsia de abarcar o fenômeno imagético, é erguido um discurso pontuado pelo domínio de um repertório diverso, cuja 
maestria mais encobre a imagem, perdida entre a erudição e citações, do que nos abre à sua descoberta.

A contramedida para equilibrar essa tendência residiria numa maior sensibilidade ao que, na leitura da imagem, existe de pontual e contextual, terreno esse em que o psicólogo, em geral detido sobre o que há de individual e particular nos fenômenos, poderia avançar com desenvoltura e sem embaraço. Trata-se certamente de um equilíbrio delicado e o risco de vacilarmos entre a iconologia e a ideologia ainda se mantém no horizonte, vide o caso de autores que tomaram o caminho inverso, de domínios externos à psicologia para a própria psicologia, com a mesma expectativa de composição de uma narrativa mestra capaz de dar conta das imagens. Na história da arte, por exemplo, Ian Verstegen (2006) propõe uma iconologia cognitiva cujo modelo para a interpretação da imagem se baseia numa teoria psicológica, o gestaltismo e, em particular, o desenvolvido por Arnheim. A psicologia da arte do autor é eleita como a chave privilegiada na compreensão do fenômeno imagético. Nesse caso, ao fazer da psicologia uma ideologia no estudo da imagem, a iconologia cognitiva se revela de fato uma ideologia psicológica (ou um psicologismo ideológico).

A proposta de Mitchell surge então de modo significativo para contornarmos essas tendências. Propõe justamente uma iconologia crítica, que expõe a crise nas grandes narrativas interpretativas mediante a análise ideológica da iconologia. Mais do que propor uma nova narrativa mestra, o autor procura destacar as particularidades em diferentes modos de tratamento da imagem. Em Iconology, Mitchell (1986) se detém sobre os modos de trabalho de autores diversos: Nelson Goodman, Ernst Gombrich, Lessing, Marx. Em Picture theory, Mitchell (1994) aborda diferentes tipos de imagens, das ilustrações em jornais às pinturas. Em nosso caso, de um projeto iconológico voltado particularmente às imagens produzidas pela psicologia, enfrentaremos o desafio de constituir uma iconologia sem transformá-la numa ideologia, trabalhando com diferentes projetos de pesquisa psicológica cuja metodologia envolveu algum tipo de recurso visual (desenhos, fotografias, vídeos etc.) e cuja produção resultante foi organizada não apenas sob a forma textual, como também sob a forma imagética.

\section{Quadro Geral dos Estudos sobre a Imagem na Psicologia}

A tarefa de catalogação de laboratórios ou grupos na psicologia que têm baseado seus projetos de pesquisa nos métodos visuais e na produção de imagens representou um passo preparatório à organização do campo da psiconologia. O procedimento primeiro para obtenção desse catálogo foi a circunscrição das ocorrências do fenômeno imagético no contexto da pesquisa psicológica. Para tanto, fizemos um levantamento do quadro geral de trabalhos com imagens no campo da psicologia, tomando como base a Avaliação CAPES 2012, em particular os projetos de pesquisa que integram o caderno de indicadores dos programas de pós-graduação em psicologia. Nessa consulta, elegemos seis descritores associados ao fenômeno imagético: arte, cinema, filme, fotografia, imagem e vídeo; e observamos a ocorrência desses termos nos resumos dos projetos de pesquisa listados pelos programas de pós-graduação. $\mathrm{Na}$ tabela 1, apresentamos os números totais desse primeiro levantamento:

Os descritores podiam ocorrer isoladamente ou repetidamente num mesmo resumo de projeto, razão pela qual a soma de suas ocorrências não equivale ao total de projetos em destaque. Os totais apresentados de 171 e 54 correspondem, respectivamente, apenas aos projetos cujos resumos incluíam algum dos seis descritores e aos programas que sediavam tais projetos. Portanto, eles não representam a totalidade de projetos de pesquisa e de programas de pósgraduação em psicologia constantes na Avaliação CAPES 2012.

Os seis descritores eram empregados com sentidos específicos e, em alguns casos, não envolviam necessariamente o fenômeno imagético. Por exemplo, o descritor "arte" incluía também os fenômenos musical e literário. Ele podia até ser encontrado em resumos de projetos que estabeleciam aproximações entre a experiência estética com obras de arte e o trabalho clínico. Já o descritor "imagem" nos apresentava a outra nuance. Ele podia se referir tanto a um tipo de imagem exterior, público, que requisitava um suporte físico para sua apreensão e veiculação, como a um tipo interior, privado, que podia existir apenas enquanto produto mental, não necessitando de um suporte material, ao menos não da maneira habitual como definimos os meios de veiculação de

Tabela 1

Número de Ocorrências dos Seis Descritores Revisados nos Resumos dos Projetos de Pesquisa Elencados pelos Programas de Pós-Graduação em Psicologia no Caderno de Indicadores da Avaliação CAPES 2012

Número de ocorrências dos descritores

136

136

Cinema
Filme

Fotografia

\begin{tabular}{lccccccc} 
Arte & Cinema & Filme & Fotografia & Imagem & Vídeo & & \\
\hline 136 & 35 & 48 & 36 & 114 & 92 & 171 & 54 \\
\hline
\end{tabular}

Número de projetos cujos resumos contêm algum dos seis descritores
Número de programas de pósgraduação em psicologia no Brasil que sediam tais projetos 
imagens, pois há autores, como o historiador da arte Hans Belting (2006), que incluem entre as mídias o próprio corpo, tomado como suporte vivo das imagens mentais. Por fim, em relação aos descritores cinema, filme, fotografia e vídeo, havia uma aproximação entre eles ao remeterem a imagens produzidas por cineastas, fotógrafos ou videoartistas, profissionais ou amadores, cujas obras passavam pela análise dos pesquisadores. Outra aproximação, desta vez não envolvendo o descritor cinema, foi encontrada quando os descritores filme, fotografia e vídeo remetiam a imagens decorrentes de registros nesses três suportes, produzidos por pesquisadores ou participantes no âmbito de projetos de pesquisa.

\section{Levantamento das Abordagens do Fenômeno Imagético na Psicologia}

A variedade de contextos em que os seis descritores apareciam revelou a existência de diferentes abordagens do fenômeno imagético no campo da psicologia. Para poder operar com tal variedade e delimitar com mais precisão o catálogo de laboratórios ou grupos que se baseiam em métodos visuais e mantêm uma produção imagética, nosso procedimento segundo consistiu em descartar, dos 171 projetos cujos resumos continham algum dos seis descritores, aqueles que, como observamos, não tratavam do fenômeno imagético. Em seguida, fizemos um recorte, dentro dos 147 projetos restantes, baseado na identificação de unidades temáticas.

Para operar tal identificação, mantivemo-nos nas linhas da iconologia de Mitchell e empreendemos uma revisão crítica dos textos, organizando-os mediante o reconhecimento de padrões discursivos que marcam a retórica dos autores na consideração do fenômeno imagético. Tínhamos como ordenadores de leitura as questões levantadas na introdução de nosso trabalho: Como se dá o processo de produção de imagens na psicologia? Por que o psicólogo recorre agora a imagens além de textos? Quais os significados por ele atribuídos aos recursos visual e textual? (Há diferença entre ambos? Qual é o particular atribuído à imagem produzida? Qual é o particular atribuído ao texto produzido?).

Seis foram as unidades identificadas por nossa análise dos resumos dos projetos, dispostas a seguir nas tabelas numeradas de 2 a 7.

A primeira unidade temática, apresentada na tabela 2 , trata de um tipo de imagem relacionada a atividades mentais. Essa relação foi identificada em resumos que atrelavam o fenômeno imagético ao estudo do pensamento, da cognição, da imaginação ou de imagens mentais. Trata-se de imagens que surgem como produto da atividade mental e, portanto, são de um tipo interior, privado, o que obriga os pesquisadores a investigá-las a partir do que os participantes conseguem relatar de sua atividade mental. Aqui incluímos também as neuroimagens, que, pelo contrário, são dependentes de suportes materiais externos, públicos, sendo exibidas numa tela ou impressas numa folha. Mas essa objetividade da imagem não significa que configurem uma representação de nossa atividade mental, pois, de fato, as neuroimagens oferecem apenas indícios de tal atividade a partir de representações do conteúdo de nossa caixa craniana.

A segunda unidade temática, apresentada na tabela 3, refere-se a um tipo de imagem que oferece modelos, referenciais, padrões, repertórios, valores (esses são alguns dos termos empregados pelos pesquisadores)

Tabela 2

Relação de Projetos de Pesquisa, Elencados pelos Programas de Pós-Graduação em Psicologia no Caderno de Indicadores da Avaliação CAPES 2012, Agrupados na Unidade Temática "Imagem-Mente"

\begin{tabular}{ll}
\hline Programas de pós-graduação & Projetos de pesquisa \\
\hline $\begin{array}{l}\text { FUFSE } \\
\text { (Psicologia social) }\end{array}$ & Cinema e pensamento: um encontro entre Gilles Deleuze e Glauber Rocha \\
PUC Rio & Avaliar fatores preditivos cognitivos e neuropsiquiátricos do diagnóstico precoce de demência: estudo \\
(Psicologia clínica) & Reorganização cerebral no envelhecimento, na lesão de hemisfério direito, na reabilitação e no bilinguismo: \\
& $\begin{array}{l}\text { evidências de fMRI } \\
\text { Re(h)abilitação neuropsicológica: desenvolvimento de estratégias e materiais de intervenção e estudos de } \\
\text { verificação da eficácia }\end{array}$ \\
(Psicologia) & $\begin{array}{l}\text { Avaliação neuropsicológica: adaptação e construção de instrumentos de exame das funções executivas, } \\
\text { comunicação, linguagem, atenção, percepção e memória }\end{array}$ \\
PUC-SP & A gênese da função simbólica sob o referencial da psicologia analítica \\
(Psicologia clínica) & $\begin{array}{l}\text { Autoconsciência, imagens mentais e experiências místicas: a religiosidade nos processos de (re)construção } \\
\text { do self }\end{array}$ \\
UFPE & Efeito da depressão e da vitimização sobre o pensamento contrafactual \\
(Psicologia cognitiva) & Estresse pós-traumático e psicoterapia: neuroimagens funcionais, alterações hormonais, metanálise \\
UFSCAR (Psicologia) & Epistemologia genética e reabilitação psicossocial \\
\hline USP (Neurociência e comportamento)
\end{tabular}


Tabela 3

Relação dos Projetos de Pesquisa, Elencados pelos Programas de Pós-Graduação em Psicologia no Caderno de Indicadores da Avaliação CAPES 2012, Agrupados na Unidade Temática "Imagem-Representação"

\begin{tabular}{|c|c|}
\hline Programas de pós-graduação & Projetos de pesquisa \\
\hline USP (Neurociência e comportamento) & Estudo dos transtornos do comportamento alimentar \\
\hline USP-RP (Psicobiologia) & $\begin{array}{l}\text { Determinantes ambientais do comportamento alimentar e imagem corporal } \\
\text { Estado nutricional e imagem corporal }\end{array}$ \\
\hline PUCCAMP (Psicologia) & $\begin{array}{l}\text { Estudo exploratório de produções imaginativas sobre a maternidade a partir de narrativas da cultura } \\
\text { brasileira }\end{array}$ \\
\hline \multirow{4}{*}{ PUC Goiás (Psicologia) } & $\begin{array}{l}\text { Tratamento multidisciplinar: qualidade de vida, fatores comportamentais e bioquímicos de pais e } \\
\text { crianças obesas }\end{array}$ \\
\hline & Determinação empírica de níveis de reforço utilitário e informativo de destinos turísticos \\
\hline & $\begin{array}{l}\text { Linhas e entrelinhas: marcas de gênero, sexualidades e intersecções em livros didáticos para o ensino } \\
\text { médio brasileiro }\end{array}$ \\
\hline & Saindo do armário? Gênero e sexualidade na mídia: discursos e imagens sobre o universo LGBT \\
\hline $\begin{array}{l}\text { PUC Rio } \\
\text { (Psicologia clínica) }\end{array}$ & $\begin{array}{l}\text { Museu de Favela - a memória social e coletiva das comunidades a partir das histórias contadas por } \\
\text { seus moradores }\end{array}$ \\
\hline \multirow{2}{*}{$\begin{array}{l}\text { PUC-RS } \\
\text { (Psicologia) }\end{array}$} & $\begin{array}{l}\text { A identidade de mulheres encarceradas: as especificidades da criminalidade feminina e da vida no } \\
\text { encarceramento }\end{array}$ \\
\hline & Construções do feminino: movimentos sociais, identidades e contextos \\
\hline $\begin{array}{l}\text { PUC-SP } \\
\text { (Psicologia clínica) }\end{array}$ & Corpo e vida urbana \\
\hline \multirow{2}{*}{$\begin{array}{l}\text { UCDB } \\
\text { (Psicologia) }\end{array}$} & Anorexia e bulimia nervosa em universitárias \\
\hline & Representações sociais em moda \\
\hline UFES (Psicologia) & Vivendo no mundo rural: educação coletiva e identidade social \\
\hline \multirow{3}{*}{$\begin{array}{l}\text { UFF } \\
\text { (Psicologia) }\end{array}$} & $\begin{array}{l}\text { O que a arte ensina para a psicanálise? O processo de subjetivação através do cinema, da literatura, } \\
\text { das artes e do teatro }\end{array}$ \\
\hline & Passagens e fronteiras - uma história de vida - parte 2 \\
\hline & Trabalho, valores, contextos sociais e história de vida intergeracional \\
\hline \multirow{4}{*}{$\begin{array}{l}\text { UFJF } \\
\text { (Psicologia) }\end{array}$} & $\begin{array}{l}\text { Desenvolvimento e validação de escalas de imagem corporal e comportamento alimentar para atletas } \\
\text { brasileiros }\end{array}$ \\
\hline & Ditadura da imagem \\
\hline & $\begin{array}{l}\text { Influências do período básico do curso de formação de sargentos na imagem corporal de homens que } \\
\text { ingressam no exército brasileiro }\end{array}$ \\
\hline & Nível de atividade física e insatisfação com a imagem corporal de universitários \\
\hline UFMG (Psicologia) & Adolescência, sexualidade e corpo nas redes sociais virtuais \\
\hline UFPA (Psicologia) & Processos identificatórios e diversidade cultural \\
\hline \multirow{2}{*}{$\begin{array}{l}\text { UFRJ } \\
\text { (Psicologia) }\end{array}$} & Imaginário e representações sociais do Brasil \\
\hline & Representações sociais no contemporâneo: diálogos conceituais \\
\hline \multirow{2}{*}{$\begin{array}{l}\text { UFRJ } \\
\text { (Teoria psicanalítica) }\end{array}$} & As relações entre o perdão, a culpa e a vergonha \\
\hline & Psicanálise e saúde mental: dispositivos clínicos para responder ao mal-estar contemporâneo \\
\hline \multirow{2}{*}{$\begin{array}{l}\text { UFRN } \\
\text { (Psicologia) }\end{array}$} & $\begin{array}{l}\text { Cuidado, escola! Ambiência e qualidade socioambiental em escolas da rede pública de ensino } \\
\text { fundamental e médio }\end{array}$ \\
\hline & Percepção de Estigma e Qualidade de Vida em Crianças com Neoplasia \\
\hline UFSC (Psicologia) & Corpo, linguagem e subjetividade: representação e imaginário no/do cinema \\
\hline UFU (Psicologia) & Exclusão e subjetividade \\
\hline $\begin{array}{l}\text { UNB } \\
\text { (Psicologia social) }\end{array}$ & Self em diferentes contextos: autoestima na escola e satisfação com autoimagem corporal \\
\hline USP (Neurociência e comportamento) & Estudo dos transtornos do comportamento alimentar \\
\hline \multirow{2}{*}{$\begin{array}{l}\text { USP } \\
\text { (Psicologia escolar e do desenvolvimento } \\
\text { humano) }\end{array}$} & Estratégias diagnósticas e propostas preventivas \\
\hline & Violência e formação no mundo administrado: mediações da constituição do indivíduo \\
\hline $\begin{array}{l}\text { USP } \\
\text { (Psicologia social) }\end{array}$ & $\begin{array}{l}\text { Periurbanidades: estudo psicossocial sobre as dinâmicas da identidade e sua construção histórica. } \\
\text { Uma comparacão de modelos urbanos na Franca e no Brasil }\end{array}$ \\
\hline
\end{tabular}




\begin{tabular}{ll}
\hline Programas de pós-graduação & Projetos de pesquisa \\
\hline USP-RP (Psicobiologia) & Determinantes ambientais do comportamento alimentar e imagem corporal \\
& Estado nutricional e imagem corporal \\
USP-RP (Psicologia) & Fatores ambientais no estabelecimento de hábitos alimentares em crianças e adolescentes \\
\hline
\end{tabular}

subjacentes à representação de si (subjetividade, identidade, personalidade) ou de uma coletividade (a imagem que fazemos do Brasil, por exemplo). Trata-se de imagens que existem independentemente de suportes materiais exteriores, públicos, e das quais eventualmente sabemos da existência a partir de relatos. As pesquisas investigam justamente o que as pessoas são capazes de relatar da imagem que fazem de si mesmas, da imagem que têm do próprio corpo ou de imagens concernentes ao grupo, coletivo, social, como a imagem da cidade e do campo, o status social, a imagem de gênero, a imagem socioambiental, entre outros objetos investigados pelos projetos reunidos neste agrupamento.

A terceira unidade temática, apresentada na tabela 4, volta-se a um tipo de imagem que necessariamente envolve suporte exterior, público, servindo como estímulo visual aos participantes das pesquisas com objetivos diversos: produção de respostas em situações experimentais; formação de impressões e tomada de decisões diante de situaçõesproblema propostas pelos pesquisadores; apreensão, interpretação e apropriação de conteúdos. Aqui também se incluem investigações sobre testes projetivos, cujas imagens assumem o mesmo sentido estimulante, evocando associações nos participantes.

A quarta unidade temática, apresentada na tabela 5, compreende um tipo de imagem que serve na coleta de dados para registrar um comportamento específico ou a interação entre participantes numa determinada situação experimental ou cotidiana. Tais registros em fotografia ou em vídeo são saudados pelos pesquisadores como recurso adicional ou até mesmo substituto da observação direta pela vantagem de oferecer múltiplas revisões dos comportamentos ou das interações investigadas e permitir a execução de análises minuciosas sobre elas.

A quinta unidade temática, apresentada na tabela 6 , refere-se ao caráter expressivo da imagem. Os pesquisadores tomam filmes, vídeos, fotografias, objetos artísticos como expressões de experiências traumáticas, do sofrimento, da individualidade, da pessoalidade, da subjetividade, da persona, da anima, do feminino, da homossexualidade, do espírito de uma época, da cultura, entre outros objetos selecionados. Encontramos dois tipos de conteúdos vinculados às imagens expressivas: conteúdos pré-formados, constituídos de antemão, mas ainda não revelados, que ficam então imbuídos nas formas de uma imagem, seja num nível individual (aqui são incluídos projetos envolvendo a análise psicológica de obras de arte ou mesmo de imagens produzidas em contextos clínicos, como no caso das técnicas expressivas de exame psicológico, que tomam as produções gráficas como recursos ilustrativos do mundo interior dos pacientes), seja num nível social (aqui se incluem as tentativas de análise de sintomas culturais, fenômenos sociais, intuídos com maior ou menor consciência pelos produtores de imagens e obras de arte e dos quais eles se tornam porta-vozes); e conteúdos processuais, em marcha, mobilizados no decorrer da produção de imagens. Nesse segundo caso, os projetos definem o ato de produzir imagens não apenas pela produção de um objeto como também de um sujeito. Certamente não se trata de um sujeito definido de antemão, oculto num mundo interior, mas de um sujeito cuja existência é definida pela abertura e progressão, o que marca a ideia de processos de subjetivação.

A sexta unidade temática, apresentada na tabela 7 , refere-se a um tipo de imagem que não está restrito às fases de coleta e análise de dados e é adotado com vistas ao desenvolvimento de uma produção imagética. O que diferencia esse agrupamento de projetos de pesquisa é o recurso aos métodos visuais associado à busca por formas alternativas de produção científica, que envolvam mais os participantes no processo de pesquisa (caso das metodologias participativas) e resultem não apenas na produção de textos como também de imagens. Aqui nos deparamos com nosso objeto particular, as imagens produzidas pela psicologia, inseridas num debate sobre o caráter da imagem e do texto que poderá ser cotejado com a iconologia crítica desenvolvida por Mitchell.

\section{Associações Iconológicas do Fenômeno Imagético na Psicologia}

As unidades temáticas que identificamos podem ser usadas para o delineamento de seis campos distintos de abordagem do fenômeno imagético no interior da psicologia, pautados por associações específicas entre imagens e discursos: (1) imagem-mente: a imagem associada a discursos referentes à atividade mental; (2) imagemrepresentação: a imagem associada a discursos referentes a valores representacionais; (3) imagem-estímulo: a imagem associada a discursos referentes a efeitos estimulantes; (4) imagem-registro: a imagem associada a discursos referentes a propriedades documentais; (5) imagem-expressão: a imagem associada a discursos referentes a conteúdos expressivos; (6) imagem-produção: a imagem associada a discursos referentes a contextos produtivos. Cada um 
Tabela 4

Relação dos Projetos de Pesquisa, Elencados pelos Programas de Pós-Graduação em Psicologia no Caderno de Indicadores da Avaliação CAPES 2012, Agrupados na Unidade Temática "Imagem-Estímulo"

\begin{tabular}{|c|c|}
\hline Programas de pós-graduação & Projetos de pesquisa \\
\hline $\begin{array}{l}\text { FUFSE } \\
\text { (Psicologia social) }\end{array}$ & $\begin{array}{l}\text { Despersonalização dos negros nos serviços de saúde: desumanização e racismo } \\
\text { Preconceito implícito: a relação entre professores e funcionários de uma universidade pública }\end{array}$ \\
\hline PUC Goiás (Psicologia) & $\begin{array}{l}\text { Comportamento do consumidor em turismo: determinação empírica dos níveis reforçadores } \\
\text { utilitário e informativo de destinos turísticos dos municípios indutores }\end{array}$ \\
\hline $\begin{array}{l}\text { PUC Rio } \\
\text { (Psicologia clínica) }\end{array}$ & Psicólogos do futuro: divulgação das interfaces entre psicologia e neurociências \\
\hline $\begin{array}{l}\text { PUC-RS } \\
\text { (Psicologia) }\end{array}$ & $\begin{array}{l}\text { Processamento de Emoções em Faces de Bebês: Adaptação e Validação de um Banco de } \\
\text { Imagens }\end{array}$ \\
\hline UEL (Análise do comportamento) & Variáveis que afetam comportamentos emergentes \\
\hline $\begin{array}{l}\text { UEM } \\
\text { (Psicologia) }\end{array}$ & $\begin{array}{l}\text { A relação entre as categorias marxistas e a psicologia histórico-cultural: revelações a partir do } \\
\text { cinema contemporâneo }\end{array}$ \\
\hline $\begin{array}{l}\text { UFES } \\
\text { (Psicologia) }\end{array}$ & $\begin{array}{l}\text { Indicadores do processo reflexivo de decodificação da comunicação não verbal em adultos } \\
\text { jovens e adultos }\end{array}$ \\
\hline UFPA (Teoria e pesquisa do comportamento) & $\begin{array}{l}\text { Escola experimental de primatas: discriminações condicionais entre estímulos naturais em } \\
\text { Cebus apella }\end{array}$ \\
\hline $\begin{array}{l}\text { UFRN } \\
\text { (Psicologia) }\end{array}$ & $\begin{array}{l}\text { Trekking como estratégia de qualidade de vida: um direito à inclusão social de deficientes } \\
\text { visuais }\end{array}$ \\
\hline UNICEUB (Psicologia) & Identidades sociais, diversidade e preconceito \\
\hline UNIR (Psicologia) & Produção, aplicação e avaliação de vídeos educativos para o ensino da ciência \\
\hline $\begin{array}{l}\text { USP-RP } \\
\text { (Psicologia) }\end{array}$ & $\begin{array}{l}\text { Orientação profissional, educação e desenvolvimento de carreira: diagnóstico e intervenção } \\
\text { Teste de fotos de profissões (BBT-Br): evidências de validade, precisão e normas em } \\
\text { diferentes contextos socioculturais }\end{array}$ \\
\hline
\end{tabular}

dos seis campos nos remetem a debates sobre a imagem marcados por associações iconológicas específicas.

Por imagem-mente, compreendemos as imagens que não são produzidas, mas inferidas. Com exceção das neuroimagens, que possuem um suporte figurativo de exibição, envolvem mais a produção discursiva sobre o fenômeno mental. Temos aqui um tipo de discurso que historicamente esteve presente na constituição da psicologia, por exemplo, na consideração da imagem como produto da atividade perceptiva e mnêmica. A necessidade de dispor da neuroimagem, além da produção discursiva do fenômeno mental, reside numa aposta na materialidade, na aparente fidedignidade do suporte físico, embora, como já afirmamos, a neuroimagem não seja a própria representação do fenômeno mental, oferecendo apenas um indício de tal mistério insondável dado no interior do corpo. Para fins de sistematização desta unidade temática, depreendemos que o recurso à neuroimagem se pauta numa lógica positivista, enquanto o tratamento do fenômeno mental por via meramente discursiva, em geral, organiza-se por uma perspectiva mais metafísica.

Por imagem-representação, compreendemos imagens que envolvem necessariamente a produção discursiva, pois delas temos apenas conhecimento mediante relatos. $\mathrm{O}$ termo "imagem" remete mais a uma produção discursiva capaz de sintetizar certa categoria, em geral, relativa a um fenômeno social. Aqui, portanto, a imagem tem, em geral, existência independente do suporte figurativo. De certo modo, equipara-se à imagem-mente, na medida em que ensaia dar forma a um fenômeno intangível, neste caso, nem tanto corporal, mas componente do tecido social. Dado o caráter imaterial de tais categorias, eventualmente, o recurso à fotografia e ao vídeo é defendido, assumindo uma função ilustrativa para amparar o texto na representação das categorias investigadas. Mas aqui, longe de uma ambição positivista, tais recursos envolvem mais a atribuição de um caráter sintético à imagem, em oposição ao caráter analítico do texto.

Por imagem-estímulo, compreendemos as imagens que não são necessariamente produzidas por psicólogos (muito menos por participantes de pesquisas). Aqui também há claramente uma delimitação entre os significados atribuídos aos recursos visual e textual. No emprego da imagem, opera a suposição de que elas apelam mais aos afetos dos participantes, diferente de textos, que caso tomados como estímulos associativos, apelariam ao intelecto.

Por imagem-registro, compreendemos as imagens que são produzidas por psicólogos, mas raramente por participantes de pesquisas. Junto com os entusiastas da neuroimagem, partilham de um discurso positivista, baseado na consideração da imagem como uma cópia fidedigna do vivido, daí as análises minuciosas e repetitivas do material. O que justifica essa aposta no caráter fidedigno da imagem reside no entendimento de que a imagem guardaria o 
Tabela 5

Relação dos Projetos de Pesquisa, Elencados pelos Programas de Pós-Graduação em Psicologia no Caderno de Indicadores da Avaliação CAPES 2012, Agrupados na Unidade Temática "Imagem-Registro"

\begin{tabular}{|c|c|}
\hline Programas de pós-graduação & Projetos de pesquisa \\
\hline $\begin{array}{l}\text { PUC Rio } \\
\text { (Psicologia clínica) }\end{array}$ & Autismo, comunicação e intervenção \\
\hline UEL (Análise do comportamento) & Senso de presença em ambientes virtuais \\
\hline $\begin{array}{l}\text { UEM } \\
\text { (Psicologia) }\end{array}$ & $\begin{array}{l}\text { Formação e atuação de pesquisadores de pós-graduação strictu sensu: estudo das ações } \\
\text { acadêmico-científicas do programa de pós-graduação em psicologia da UEM - projeto } \\
\text { memória }\end{array}$ \\
\hline $\begin{array}{l}\text { UERJ } \\
\text { (Psicologia social) }\end{array}$ & Subjetividade, saúde e trabalho na escola pública: conhecer para transformar \\
\hline $\begin{array}{l}\text { UFAL } \\
\text { (Psicologia) }\end{array}$ & $\begin{array}{l}\text { Emergência de self e linguagem } \\
\text { Sentidos de regras do jogo e do funcionamento escolar por crianças na educação } \\
\text { infantil }\end{array}$ \\
\hline $\begin{array}{l}\text { UFES } \\
\text { (Psicologia) }\end{array}$ & Brincadeiras e jogos tradicionais no Espírito Santo: crianças de ontem e de hoje \\
\hline $\begin{array}{l}\text { UFPA } \\
\text { (Psicologia) }\end{array}$ & $\begin{array}{l}\text { Percepção de crianças de abrigo: os espaços e as formas relacionais } \\
\text { Crianças em acolhimento institucional: um estudo das suas percepções }\end{array}$ \\
\hline UFPA (Teoria e pesquisa do comportamento) & $\begin{array}{l}\text { Juventude e gênero no contexto do movimento hip hop da cidade de Recife } \\
\text { Relações sociais, rotinas e valores culturais infantis: compreensão da criança e olhar } \\
\text { do adulto } \\
\text { Compreendendo os sistemas de representação: a família como exemplo }\end{array}$ \\
\hline $\begin{array}{l}\text { UFRJ } \\
\text { (Psicologia) }\end{array}$ & $\begin{array}{l}\text { Encontros multissensoriais } \\
\text { Psicoterapia e reinserção social: programa de pesquisas em psicoterapias baseadas em } \\
\text { evidências para transtornos psiquiátricos }\end{array}$ \\
\hline UFRN (Psicobiologia) & Ecologia e comportamento do boto cinza, Sotalia fluviatilis \\
\hline UFRRJ (Psicologia) & Vínculos afetivos no ciclo de vida: desenvolvimento e saúde \\
\hline UFSC (Psicologia) & A elaboração de conceitos científicos em pessoas com deficiência visual \\
\hline $\begin{array}{l}\text { UFSCAR } \\
\text { (Psicologia) }\end{array}$ & Intervenção com mães denunciadas por maus tratos: efeitos de recursos tecnológicos \\
\hline UNB (Processos de desenvolvimento humano e saúde) & Comunicação e metacomunicação nas interações criança-criança e professor-aluno \\
\hline UNB (Psicologia clínica e cultura) & Psicanálise, autismo e prevenção em saúde mental materno infantil \\
\hline UNIFIEO (Psicologia educacional) & Repercussões das práticas sociais na formação do sujeito \\
\hline UNIR (Psicologia) & A inclusão escolar na percepção do aluno com surdez \\
\hline UNISINOS (Psicologia) & $\begin{array}{l}\text { A clínica com o bebê: um estudo sobre os sintomas psicofuncionais em crianças com } \\
\text { histórico de internação neonatal } \\
\text { Maternidade, relação mãe-bebê e desenvolvimento infantil no contexto da } \\
\text { prematuridade }\end{array}$ \\
\hline USP (Psicologia escolar e do desenvolvimento humano) & Políticas públicas de saúde na cidade de São Paulo: propostas e práticas \\
\hline $\begin{array}{l}\text { USP-RP } \\
\text { (Psicologia) }\end{array}$ & $\begin{array}{l}\text { Intervenção não farmacológica no alívio da dor em recém-nascido pré-termo: avaliação } \\
\text { do efeito de solução de sacarose em doses repetidas } \\
\text { As múltiplas redes de significações constituintes dos e constituídas pelos dialéticos } \\
\text { processos de inclusão/exclusão de crianças com necessidades especiais }\end{array}$ \\
\hline
\end{tabular}

frescor do vivido, o qual num relato se perderia com a reprodução mediante palavras. Há dois pressupostos aqui, o da supremacia da imagem na qualidade de registro (o que da experiência se esvai ao ser vertido em palavras é preservado na imagem, que guarda inclusive seus mínimos detalhes) e o da subjetividade do texto (o que da experiência é variável conforme as diferentes cabeças e sentenças de quem a narra não varia com a imagem, como se um narrador fosse menos confiável do que uma imagem).

Por imagem-expressão, compreendemos justamente o oposto, que as imagens também carregam uma marca subjetiva. Por intermédio delas, abre-se o mundo privado 
Tabela 6

Relação dos Projetos de Pesquisa, Elencados pelos Programas de Pós-Graduação em Psicologia no Caderno de Indicadores da Avaliação CAPES 2012, Agrupados na Unidade Temática "Imagem-Expressão"

\begin{tabular}{|c|c|}
\hline Programas de pós-graduação & Projetos de pesquisa \\
\hline PUC Rio (Psicologia clínica) & Conjugalidade e parentalidade na clínica com famílias \\
\hline $\begin{array}{l}\text { PUC-SP } \\
\text { (Psicologia clínica) }\end{array}$ & $\begin{array}{l}\text { Aspectos psicopatológicos e metapsicológicos da clínica psicanalítica contemporânea } \\
\text { Psicopatologia fundamental } \\
\text { Psicopatologia e técnica na clínica psicanalítica winnicottiana } \\
\text { Arte e cultura } \\
\text { Psicologia analítica e arte } \\
\text { Criação, resistência e cura } \\
\text { Lygia Clark entre arte e clínica } \\
\text { Pensamento, corpo e devir } \\
\text { Política da subjetividade }\end{array}$ \\
\hline $\begin{array}{l}\text { PUC-SP } \\
\text { (Psicologia social) }\end{array}$ & $\begin{array}{l}\text { Álbuns de bebê: a pessoalidade na confluência de tecnologias e sociabilidades em uma perspectiva } \\
\text { transgeracional } \\
\text { Estratégias para a análise de práticas discursivas }\end{array}$ \\
\hline UERJ (Psicanálise) & Psicanálise e arte \\
\hline UERJ (Psicologia social) & O cinema psicológico de Fernando Meireles \\
\hline $\begin{array}{l}\text { UFBA } \\
\text { (Psicologia) }\end{array}$ & $\begin{array}{l}\text { O sistema de pensamento freudiano para o desenvolvimento de epistemologias não-cartesianas em artes e } \\
\text { humanidades }\end{array}$ \\
\hline $\begin{array}{l}\text { UFF } \\
\text { (Psicologia) }\end{array}$ & $\begin{array}{l}\text { Fronteiras e limiares da diferença na cidade: a ética da imagem nos documentários brasileiros } \\
\text { Incidências biopolíticas no chão da escola - um estudo sobre práticas substitutivas à medicalização da vida } \\
\text { escolar } \\
\text { Variações sobre o ver e o não ver }\end{array}$ \\
\hline $\begin{array}{l}\text { UFMA } \\
\text { (Psicologia) }\end{array}$ & $\begin{array}{l}\text { A crítica hermenêutica à ideia de ciência moderna e o problema de ressignificação da verdade, a partir da } \\
\text { experiência da arte }\end{array}$ \\
\hline $\begin{array}{l}\text { UFRGS } \\
\text { (Psicologia social e institucional) }\end{array}$ & $\begin{array}{l}\text { Corpo, arte e clínica nos modos de trabalhar e subjetivar } \\
\text { Utopia, arte e psicanálise: aparelhos óticos do contemporâneo }\end{array}$ \\
\hline $\begin{array}{l}\text { UFRJ } \\
\text { (Psicologia) }\end{array}$ & $\begin{array}{l}\text { Atualizando virtualidades: arte e produção de subjetividade com pessoas com deficiência visual } \\
\text { Cognição inventiva: experiências artísticas, processos coletivos e produção de subjetividade } \\
\text { Práticas artísticas e construção da cidadania com pessoas deficientes visuais } \\
\text { Projeto brincante } \\
\text { Redes de controle e vigilância - um observatório para o acompanhamento de subjetivações sócio-técnicas }\end{array}$ \\
\hline $\begin{array}{l}\text { UFRN } \\
\text { (Psicologia) }\end{array}$ & $\begin{array}{l}\text { Coletivos juvenis: problematizando as possibilidades de resistência social e produção de saúde nas periferias } \\
\text { urbanas } \\
\text { Saúde mental, cultura e arte: reinventando a vida na cidade de Natal }\end{array}$ \\
\hline $\begin{array}{l}\text { UFSJ } \\
\text { (Psicologia) }\end{array}$ & $\begin{array}{l}\text { Núcleo de estudo, pesquisa e intervenção em saúde } \\
\text { Psicologia e arte: reflexões acerca da subjetividade obstada }\end{array}$ \\
\hline $\begin{array}{l}\text { UNB } \\
\text { (Psicologia clínica e cultura) }\end{array}$ & $\begin{array}{l}\text { A eficácia analítica na clínica, na teoria e em suas relações com a arte } \\
\text { Sobre psicanálise, subjetivação contemporânea, arte e cultura }\end{array}$ \\
\hline $\begin{array}{l}\text { UNESP Assis } \\
\text { (Psicologia) }\end{array}$ & $\begin{array}{l}\text { A experiência estética no contexto do atendimento psicoterápico: dimensões sensíveis da escuta clínica } \\
\text { Éticas-estéticas-políticas das (homos)sexualidades, gêneros e homofobia na cinematografia brasileira e das } \\
\text { Américas }\end{array}$ \\
\hline UNICAP (Psicologia clínica) & A psicanálise freudiana - uma introdução \\
\hline $\begin{array}{l}\text { UNIFOR } \\
\text { (Psicologia) }\end{array}$ & $\begin{array}{l}\text { Psicanálise e cultura - arte e subjetivação } \\
\text { Psicanálise na interdisciplinaridade: interrogações sobre a teoria, a clínica e o social }\end{array}$ \\
\hline $\begin{array}{l}\text { USP } \\
\text { (Psicologia clínica) }\end{array}$ & $\begin{array}{l}\text { Investigação do uso de procedimentos intermediários no atendimento clínico em grupo em pacientes com } \\
\text { transtornos psiquiátricos: ateliê de desenho de livre expressão } \\
\text { Sofrimento humano e estudo da "eficácia terapêutica" de enquadres diferenciados }\end{array}$ \\
\hline $\begin{array}{l}\text { USP (Psicologia escolar e do } \\
\text { desenvolvimento humano) }\end{array}$ & $\begin{array}{l}\text { A questão da morte nas instituições de educação: o educador, a criança e o jovem diante das perdas } \\
\text { Teoria crítica da sociedade e formação do indivíduo }\end{array}$ \\
\hline USP-RP (Psicologia) & Antropologia: islã, imagem e performance \\
\hline UTP (Psicologia) & Atividades expressivas como prática de comportamento moral \\
\hline
\end{tabular}


Tabela 7

Relação dos Projetos de Pesquisa, Elencados pelos Programas de Pós-Graduação em Psicologia no Caderno de Indicadores da Avaliação CAPES 2012, Agrupados na Unidade Temática "Imagem-Produção"

\begin{tabular}{|c|c|}
\hline Programas de pós-graduação & Projetos de pesquisa \\
\hline \multirow{2}{*}{$\begin{array}{l}\text { UFAL } \\
\text { (Psicologia) }\end{array}$} & $\begin{array}{l}\text { Pesquisa-ação com jovens em situação de vulnerabilidade psicossocial da orla lagunar em } \\
\text { Maceió: retratando a vida }\end{array}$ \\
\hline & A imagem na investigação-intervenção de processos psicossociais \\
\hline $\begin{array}{l}\text { UFC } \\
\text { (Psicologia) }\end{array}$ & $\begin{array}{l}\text { Juventudes e mídia: um estudo sobre o consumo, apropriação e produção de mídia por } \\
\text { jovens estudantes de escola pública de Fortaleza }\end{array}$ \\
\hline $\begin{array}{l}\text { UFES } \\
\text { (Psicologia institucional) }\end{array}$ & $\begin{array}{l}\text { Coisas que se passam sobre a pele da cidade: clínica urbana e políticas de subjetivação no } \\
\text { contemporâneo }\end{array}$ \\
\hline UFPE (Psicologia) & Gênero, sexo e corpo travesti: abjeções e devires \\
\hline UFRGS (Psicologia social e institucional) & Travessias: narrações da diferença - clínica, pesquisa e intervenção \\
\hline UFRJ (Psicologia) & Vídeos didáticos \\
\hline \multirow{2}{*}{$\begin{array}{l}\text { UFRJ (Psicossociologia de comunidades e ecologia } \\
\text { social) }\end{array}$} & $\begin{array}{l}\text { Imagem e cotidiano: análise e metodologia da imagem, para ver, conhecer, fazer e narrar } \\
\text { o quotidiano }\end{array}$ \\
\hline & $\begin{array}{l}\text { Memória cultural, invenção do cotidiano urbano e metodologias narrativas e participação } \\
\text { Mulheres, cultura e desenvolvimento }\end{array}$ \\
\hline \multirow{2}{*}{$\begin{array}{l}\text { UFSC } \\
\text { (Psicologia) }\end{array}$} & $\begin{array}{l}\text { ArteUrbe: oficinas estéticas com jovens e os processos de objetivação e subjetivação nas } \\
\text { tramas da comunicação urbana }\end{array}$ \\
\hline & $\begin{array}{l}\text { Corpo, arte, cidade: processos de objetivação estética e subjetivação nas tramas da } \\
\text { comunicação urbana }\end{array}$ \\
\hline $\begin{array}{l}\text { USP (Psicologia escolar e do desenvolvimento } \\
\text { humano) }\end{array}$ & $\begin{array}{l}\text { Olhares dos jovens do quilombo Ivaporunduva e comunidade caiçara Maruja sobre a } \\
\text { vida, trabalho e cultura }\end{array}$ \\
\hline
\end{tabular}

de um sujeito ou, por intermédio da produção imagética, marca-se um modo de subjetivação. Independentemente do conceito adotado nos projetos incluídos nesta unidade temática, o de subjetividade ou subjetivação, ambos mantêm um pressuposto similar ao observado nas imagens-estímulo, o de que a imagem se conforma mais à via afetiva do que à intelectual. Como as imagens aqui investigadas nem sempre foram produzidas no quadro de projetos de pesquisa, os pesquisadores se valem do acervo imagético da cultura.

Por imagem-produção, compreendemos justamente as imagens que compõe o quadro de projetos de pesquisa, mas, diferente da imagem-registro, na qual não se discute a sua autoria, aqui elas estão necessariamente inseridas num debate, caro a projetos baseados em métodos participativos, que marca a diferença caso as imagens tenham sido produzidas por psicólogos ou pelos próprios participantes de pesquisas. Nesta associação iconológica, estabelece-se o encontro entre métodos participativos e métodos visuais, pautado pela atribuição de um caráter envolvente à imagem: supostamente, ela favoreceria a adesão dos participantes, já que, diferente da produção de textos, cujo domínio envolve um caminho mais formal de ensino, a produção de imagens estaria mais aberta ao amadorismo (o que não significa que a produção imagética não requeira o domínio de uma linguagem e que esta apresente alto grau de erudição).

A psiconologia está inserida justamente no âmbito da imagem-produção. Encontramos então, dispostos na tabela 7 , os projetos mais alinhados com os debates que pretendemos levantar com a psiconologia. A partir deles pudemos finalmente organizar um catálogo de laboratórios ou grupos de pesquisa no país que recorrem aos métodos visuais e mantêm produções imagéticas, cujos coordenadores são: Adélia Augusta Souto de Oliveira (UFAL - Psicologia), Luciana Lobo Miranda (UFC - Psicologia), Leila Aparecida Domingues Machado (UFES - Psicologia institucional), Karla Galvão Adrião (UFPE - Psicologia), Analice de Lima Palombina (UFRGS - Psicologia social e institucional), Lucia Rabello de Castro (UFRJ - Psicologia), Maria Inácia d'Ávila Neto (UFRJ - Psicossociologia de comunidades e ecologia social), Andrea Vieira Zanella (UFSC - Psicologia), Lineu Noriô Kohatsu (USP - Psicologia escolar e do desenvolvimento humano).

\section{CONSIDERAÇÕES FINAIS}

O presente trabalho se propôs a introduzir um tema original na psicologia com a apresentação de um objeto de estudo (as imagens produzidas pela psicologia), a definição de um campo de investigação para tal objeto (a psiconologia) e a catalogação dos laboratórios ou grupos 
de pesquisa em psicologia no Brasil cuja produção estaria vinculada ao campo.

A continuidade na constituição do campo envolve algumas tarefas: investigar a produção desses laboratórios ou grupos de pesquisa; apreender o modo particular com que cada um deles trabalha com a produção de imagens no âmbito de seus projetos de pesquisa; observar os princípios variados que orientam a prática desses psicólogos produtores de imagens no contexto acadêmico e identificar, em tal variedade, possíveis linhas gerais definidoras do particular da psicologia no processo de produção de imagens. Apenas abrimos um caminho para a psiconologia. Aguardamos contribuições de mais pesquisadores para traçar os desígnios do campo.

\section{REFERÊNCIAS}

Andriolo, A. (2014). A política das imagens do inconsciente: psicologia social e iconologia crítica. Memorandum, 26 , 90-109.

Belting, H. (2006). Imagem, mídia e corpo: Uma nova abordagem à iconologia. Revista de Comunicação, Cultura e Teoria da Mídia, 8, 32-60.

Frayze-Pereira, J. A. (1994). A alteridade da arte: Estética e psicologia. Psicologia USP, 5(1-2), 35-60.

Ginzburg, C. (2007). De A. Warburg a E. H. Gombrich: Notas sobre um problema de método. In Mitos, emblemas, sinais. Morfologia e história (pp. 41-94). São Paulo: Companhia das Letras. (Trabalho original publicado em 1986)

Ide, D. S. (2014a). Pesquisa psicológica baseada em vídeos: Sondar o invisível a partir do fora de quadro. Temas em Psicologia, 22, 93-108.

Ide, D. S. (2014b). Perambulações no bairro da Liberdade: Passeios ao vivo e em vídeo com moradores locais (Tese de doutorado).
Instituto de Psicologia, Universidade de São Paulo, São Paulo, SP, Brasil.

Jesus, L. U. (2015). Uma pesquisa visual e compartilhada de Paraty: Fotografias e narrativas de representação da cidade (Dissertação de mestrado). Instituto de Psicologia, Universidade de São Paulo, São Paulo, SP, Brasil.

Mitchell, W. J. T. (1986). Iconology: Image, text, ideology. Chicago: University of Chicago Press.

Mitchell, W. J. T. (1994). Picture theory: Essays on verbal and visual representation. Chicago: University of Chicago Press.

Panofsky, E. (1976). Iconografia e iconologia: Uma introdução ao estudo da arte da renascença. In Significado nas artes visuais (pp. 47-87). São Paulo: Perspectiva. (Trabalho original publicado em 1955)

Verstegen, I. (2006). A plea for cognitive iconology within visual culture. Contemporary Aesthetics, 4. Recuperado de http://hdl. handle.net/2027/spo.7523862.0004.014 